\title{
CARCINOMA BREAST - DON'T MISS THE SYNCHRONOUS CARCINOMA IN THE SECOND BREAST
}

\author{
A. Ravikamal Kumar ${ }^{1}$, S. V. P. L. Chandrakumar²
}

HOW TO CITE THIS ARTICLE:

A. Ravikamal Kumar, S. V. P. L. Chandrakumar. "Carcinoma Breast - Don't Miss the Synchronous Carcinoma in the Second Breast". Journal of Evolution of Medical and Dental Sciences 2015; Vol. 4, Issue 25, March 26; Page: 4382-4385, DOI: 10.14260/jemds/2015/633

INTRODUCTION: Synchronous bilateral carcinoma of breast is rare about $1-2 \%$ incidence.[1] Occurrence of carcinoma in the second breast within 3months of detection of carcinoma in the first breast or occurring simultaneously in both breasts is considered as synchronous bilateral carcinoma breast. If the carcinoma in the $2^{\text {nd }}$ breast occurs more than 3 months after the occurrence of the index carcinoma it is considered as metachronous.[2,3] It's incidence is reported to be $5-6 \% .{ }^{[1]}$ Here we report a case of bilateral synchronous carcinoma of breast which we treated in our unit. The literature is reviewed as to it's definition, biological behaviour, treatment and prognosis.

CASE REPORT: A 50 years old female patient presented with a lump in the left breast of 1month duration. No history of bone pains, dyspnoea, haemoptysis and jaundice. No family history of breast carcinoma. On examination a $5 \mathrm{~cm}$ hard mass with irregular borders is found in the upper outer quadrant of the left breast. Clinically it is not fixed to chest wall or to pectoral muscles. No peau d' orange or skin fixity. There were two lymphnodes palpable in the left axilla which were hard in consistency and not fixed to skin or to one another or to adjacent structures. No supraclavicular lymphnodes palpable. On examination of the right breast, an ill-defined granular mass is found in the upper and outer quadrant. No lymphnodes were palpable in the right Axilla.

Mammography showed the following findings. Lt. breast- ill-defined symmetric density with powdery microcalcification Birad's category V lesion. Rt. Breast- diffuse nodularity with powdery microcalcification Birad's category V lesion. FNAC revealed duct cell carcinoma in both breasts. Blood investigations showed Hb-8gms, RBS, Blood urea, sr. creatinine Sr. alkaline phosphatase were within normal limits. Chest $\mathrm{x}$-ray showed no metastasis in the lungs, ribs or pleura. U/s of abdomen showed no secondaries in liver or ascites. No bone scan was done as it was not available in govt. general hospital.

After cardiac evaluation under general anesthesia, modified radical mastectomy was done on both breasts. Post-operative recovery was uneventful. Stitch abscess occurred at one site which was dealt with. HPE of the specimens showed the following.

Left breast- $6 \times 5 \times 5 \mathrm{~cm}$ grey white irregular tumour present. Histologic features of infiltrating duct cell carcinoma along with in situ component 30\% showing comedo \& cribriform patterns seen. Basal cut margins showed tumour infiltration. Vascular invasion present. NBR grade II. All 9 lymphnodes showed tumour deposits.

Right breast - greyish white gritty lesion of 4x2x1 cm seen. Sections showed infiltrating duct cell carcinoma with insitu component $50 \%$ showing comedo \& cribriform pattern. Margins are free. One of the axillary lymphnodes show tumour deposits. NBR score 6 grade II.

ER and PR receptors found to be negative but HER2/neu receptor is positive. 
The patient was sent to chemotherapy and radiotherapy department for further treatment. She was started on chemotherapy 4cycles of Adriamycin and cyclophosphamide followed by taxanes. While on chemotherapy after 8months the patient developed altered sensorium and convulsions and died before CT of the brain could be done.

DISCUSSION: Bilateral breast carcinoma represents a small proportion of all breast carcinoma cases. Contralateral breast carcinoma can occur synchronously or metachronously. Synchronous breast carcinoma was defined as cancer diagnosed in both breasts simultaneously or with in 3months of diagnoses of first tumour. Metachronous breast cancer was defined as the one diagnosed in the contralateral breast more than 3months after the diagnosis of the tumour in the index breast.[2,3] The reported incidence of synchronous bilateral carcinoma is approximately $1-2 \%$ and that of metachronous carcinoma is $5-6 \% \cdot{ }^{[1]}$

Is the second tumour in the contralateral breast a metastasis from the primary breast lesion $\mathrm{i}$. e. index tumour or is it a second primary breast cancer developed de novo? This question is important for the clinician as in the first case only palliative care is possible but the second can be treated radically. Most of the SBBC are independent primary tumours and not due to metastasis from primary breast lesion. Features that characterise a second primary tumour are extensive in-situ component, different histologies or different degrees of differentiation between the tumours and absence of other metastasis except regional lymphnodes. Intra $\mathrm{M}$ etal, in their prospective study of 143 cases with SBBC, showed that there is a strong correlation of extensive intraductal component between the bilateral breast tumours which implies independent tumours and excludes the metastatic origin of these tumours.[4]

Patients with bilateral breast carcinoma who present with synchronous disease are at greater risk of distant metastasis than women with unilateral or metachronous breast tumours. There is decreased overall survival and local control for patients with synchronous bilateral carcinoma compared to patients with metachronous or unilateral disease. ${ }^{[5,6]}$ Prognosis also seems to be poor when the second tumour appeared with in 2 yrs after onset of the index cancer. The longer the interval between the diagnoses of the two cases, the better is the survival rate. ${ }^{[7,8,9,10]}$

Optimal surgical management of these primary synchronous breast carcinoma is controversial. In the past these cases were treated more aggressively with bilateral MRMs with the view that the disease has poor survival and outcome. Gollamuddie et al showed that early stage SBBC can be safely treated with bilateral breast conservative surgery with outcome that appears to be comparable to that of patients with early stage unilateral breast carcinoma. ${ }^{[11,2]}$

Treatment of second breast cancer is similar to treatment of first tumour. Treatment should be appropriate for the stage of disease. Indications for complementary systemic treatment or radiotherapy are the same in the first and second breast cancer.

CONCLUSION: Although the occurrence of synchronous bilateral carcinoma breast is rare, the condition should be kept in mind and the contralateral breast should be subjected to triple assessment at the time of diagnosis of the index tumour. Thereafter the contralateral breast should be followed up by clinical examination 6monthly and mammography yearly.

As the condition is rare, multi-institutional, prospective studies with longer follow-up are needed for better understanding the synchronous bilateral breast carcinoma. 


\section{BIBLIOGRAPHY:}

1. Donovan AJ, Bilateral breast cancer. Surg Clin North Am 1990: 70: 1141-1149.

2. Jobsen JJ, Palen JV, Ong F, Meerwaldt JH. Synchronous bilateral breast cancer: prognostic value and incidence. The Breast 2003; 12: 83-88.

3. Hartman M, Czene K, Reilly M, Adolfsson J, Bergh J, Adami HO, Dickman PW, Hall P. J Clin Oncol. 2007; sep20: 25 (27): 4210-16.

4. Intra M, Rotmens ZN, Viale G, Marianit, Bonanni B, Mastropasqua MG et al. Clinicopathologic characteristics of 143 patients with synchronous bilateral invasive breast carcinomas treated in a single institution Cancer 2004; 101: 905-12.

5. Heron DE, Komarmicky LT, Hyslop T, Schwartz GE, Mansfield CM. Bilateral breast carcinoma risk factors and outcomes for patients with synchronous and metachrous disease. Cancer2000; 88: 2739-50.

6. Casmichail AR, Bendell S. The long term outcome of synchronous bilateral breast carcinoma is worse than metachronous or unilateral tumours. Eur J Surg Oncology 2002: 28: 388-391.

7. Bailey MJ, Royce C. Bilateral carcinoma of breast Br J surg 1980; 67: 114-416.

8. Microwitz M, Noy S, Lazenik N, Aladjeen D, Bilateral breast cancer. J Surg on Col 1985; 30: 109112.

9. Abdalla I, Thisted RA, Heinman R. The impact of contralateral breast cancer on the outcome of breast cancer patient treated by mastectomy. Cancer J 2000; 6: 266-272.

10. Kollias J, Ellis IO, Elston CW, Blarney RW. Prognostic significance of synchronous and metachronous bilateral breast cancer. Worl J Surg 2001; 25: 1117-1124.

11. Gollamudi SV, Gelman RS, Peiro G, Schneider LT, Schnitt SJ, REcht A, et al. Breast conserving therapy for Stage I-II synchronous bilateral breast carcinoma Cancer1997; 79: 1362-9.

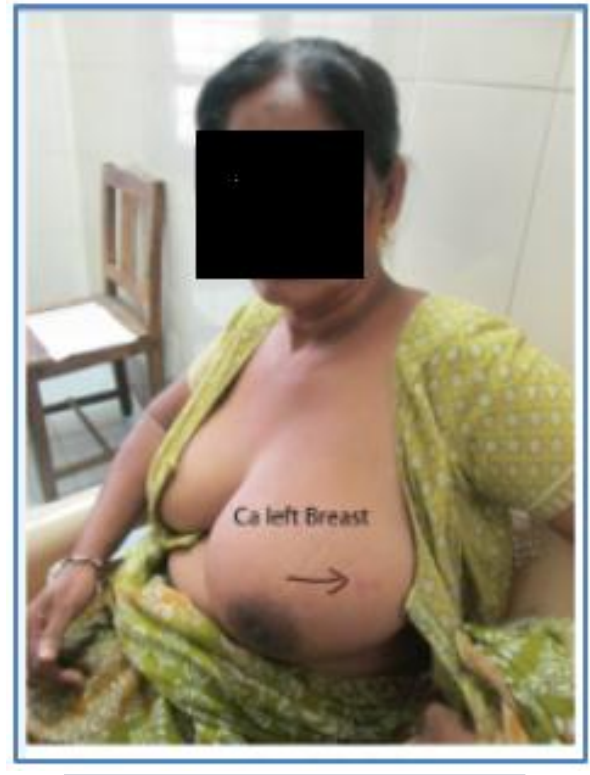

Fig. 1: Pre-Operative Clinical Picture

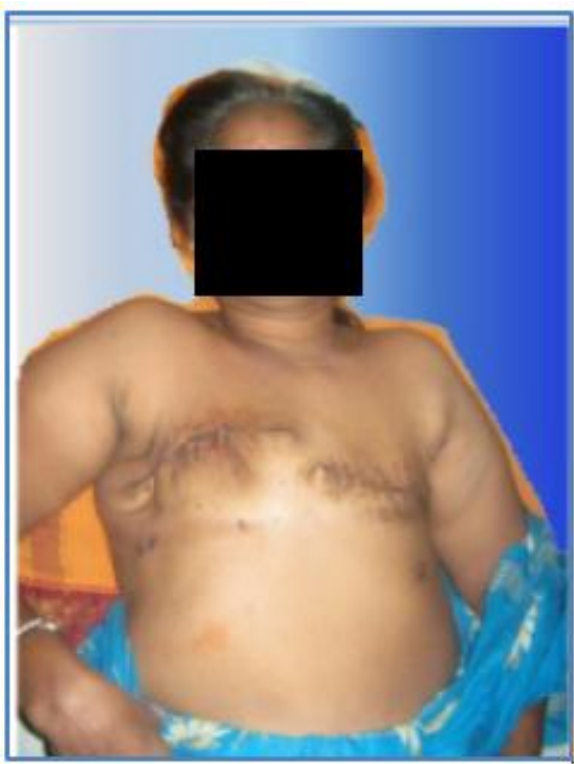

Fig. 2: Post-Operative Clinical Picture 


\section{CASE REPORT}

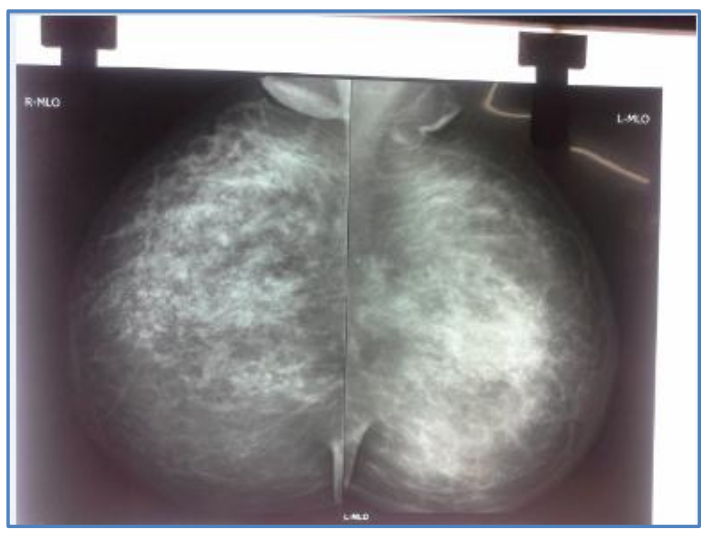

Fig. 3

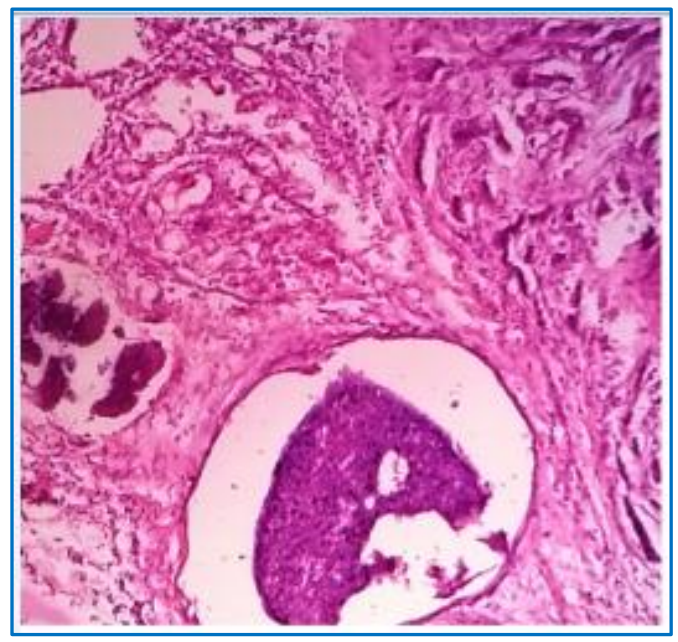

Fig. 4: HPE- Invasive duct cell carcinoma right breast with insitu component

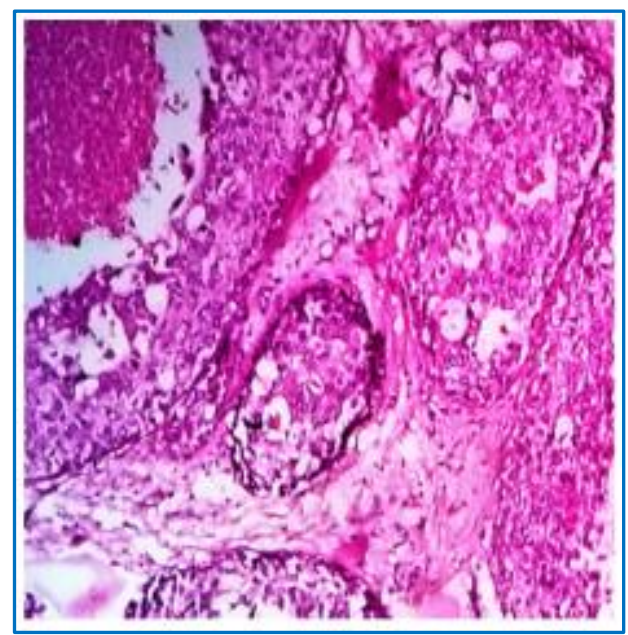

Fig. 5: HPE- Invasive ductal Carcinoma left breast

\section{AUTHORS:}

1. A. Ravikamal Kumar

2. S. V. P. L. Chandrakumar

\section{PARTICULARS OF CONTRIBUTORS:}

1. Associate Professor, Department of General Surgery, Guntur Medical College, Guntur.

2. Assistant Professor, Department of General Surgery, Guntur Medical College, Guntur.

\section{NAME ADDRESS EMAIL ID OF THE} CORRESPONDING AUTHOR:

Dr. A. Ravikamal Kumar,

Flat No. 10, Garudadri Towers, Mahakavi Sri Sri Street, Maruthi Nagar, Guntur-522006.

E-mail: ravikka@rediffmail.com

Date of Submission: 24/02/2015. Date of Peer Review: 25/02/2015. Date of Acceptance: 14/03/2015. Date of Publishing: 26/03/2015. 